\title{
Biosensor-Based Approaches for Detecting Ochratoxin A and 2,4,6-Trichloroanisole in Beverages
}

\author{
Sophia Mavrikou *,+ (D) and Spyridon Kintzios + (iD \\ Laboratory of Cell Technology, Department of Biotechnology, Agricultural University of Athens, \\ 75 Iera Odos St., 11855 Athens, Greece; skin@aua.gr \\ * Correspondence: sophie_mav@aua.gr; Tel.: +30-210-529-4292 \\ + These authors contributed equally to this work.
}

Academic Editor: Elena González-Peñas

Received: 26 January 2018; Accepted: 14 March 2018; Published: 19 March 2018

\begin{abstract}
Mycotoxins and haloanisoles are secondary metabolites produced under special conditions of temperature and humidity by fungi colonizing a variety of commodities from preharvest up to consumer use. Ochratoxin A and 2,4,6-trichloanisole are produced mainly by species of the genus Aspergillus and Penicillium. Ochratoxin A exhibits nephrotic effects and can, potentially, be associated with human carcinogenesis, whereas 2,4,6-trichloanisole is primarily responsible for cork taint in wines. This review provides an overview of recent advances in biosensor technology for the determination of the aforementioned compounds in wine, beer and other beverages, as well as cork stoppers, which help in establishing and carrying out proper product quality-management strategies. Such a detailed investigation of biosensor-based detection methods of these toxic compounds in beverages could lead to the provision of safe-to-consume products, and allow the prioritization of future research efforts.
\end{abstract}

Keywords: biosensors; ochratoxin A; 2,4,6-trichloroanisol; beverages; antibodies; aptamers

\section{Introduction}

Various low molecular weight secondary metabolites with properties that are toxic for humans and animals are produced mainly by fungi of the genera Aspergillus, Penicillium and Fusarium [1,2]. These species grow in cereals, nuts, milk, eggs, dried fruit, coffee, cocoa, spices, oil seeds, beans and several fruit types (e.g., apples), or sub-products produced from contaminated raw materials (e.g., wine, beer), as well as cork stoppers [3-5]. For example, over 400 types of mycotoxins are reported and classified by their structural similarities, their biological source, the moment of production, storage, transport or processing stages and their toxic effects [1,3]. All mycotoxins are harmful in different ways, inducing acute and chronic toxicity, such as carcinogenic toxicity, genotoxicity, mutagenicity, immunotoxicity, nephrotoxicity, hepatotoxicity and even teratogenicity $[2,6,7]$. In addition, another set of fungi-derived metabolites, haloanisoles, represent an increasingly serious source of concern for the deterioration of wine and beverage quality [8].

Modern techniques and good practices of handling and preserving food and feed have been largely developed in response to planned regulations and to reduce the presence of mycotoxins and haloanisoles. Many well-established analytical techniques such as high-performance liquid chromatography (HPLC) or gas chromatography (GC) combined with tandem mass spectrometry (MS/MS) have been developed for the analysis of the different groups of mycotoxins and individual haloanisoles [9-11]. Some limitations of these techniques involve high cost, lack of sensitivity (especially for mycotoxins), time-consuming steps such as field-sample collection, and the need for skilled technicians. Therefore, there is a necessity for complementary techniques to detect quality parameters and safety threats in rapid screening. 
Biosensors are analytical devices that convert a biological response into an electrical or optical signal through the integration of bio-recognition molecules in the construction of sensor design [12-18]. In the present review, we provide an update of emerging principles and methodological approaches for the detection of ochratoxin A and 2,4,6-trichloroanisole, two major representatives of mycotoxins and haloanisoles, respectively, being of particular interest for the wine and beverage industry. The strengths and limitations of these innovative approaches are presented, along with suggestions for future research.

\section{Biosensors for the Detection of Ochratoxin A in Wine, Beer and Other Beverages}

Ochratoxins belong to the most important and most commonly occurring mycotoxins [19]. The most prevalent and relevant fungal toxin of this group is ochratoxin A (OTA). The International Agency for Research on Cancer has classified OTA in group 2B of substances considered as possible carcinogens to humans [20]. OTA is a mycotoxin produced mainly by fungi of the genera Aspergillus and Penicillium under particular environmental conditions. Recent studies have demonstrated that OTA is frequently present in a series of beverages, particularly green coffee [21-23], beer [24,25] and wine [26-29]. This mycotoxin is nephrotoxic, hepatotoxic, genotoxic, teratogenic and immunotoxic to animals and its carcinogenicity in rats and male mice is well-established [30,31]. OTA (Figure 1a) includes a dihydrocoumarin moiety linked to a molecule of $1-\beta$-phenylalanine by an amide bond. Other compounds of OTA production are the dechlorinated analog ochratoxin B (OTB) (Figure 1b), the isocoumarin nucleus of OTA ochratoxin $\alpha(\mathrm{OT} \alpha)$ (Figure 1d), and its dechlorinated analogue ochratoxin $\beta$ (OT $\beta$ ) (Figure 1e) and ochratoxin C (OTC) (Figure 1c), which is an ethyl ester derivative of OTA.<smiles>C[C@H]1Cc2c(Cl)cc(C(=O)N[C@@H](Cc3ccccc3)C(=O)O)c(O)c2C(=O)O1</smiles>

(a)<smiles>C[C@H]1Cc2ccc(C(=O)N[C@@H](Cc3ccccc3)C(=O)O)c(O)c2C(=O)O1</smiles>

(b)

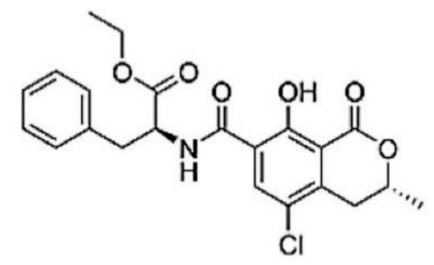

(c)<smiles>C[C@H]1Cc2c(Cl)cc(C(=O)O)c(O)c2C(=O)O1</smiles>

(d)<smiles>C[C@H]1Cc2ccc(C(=O)O)c(O)c2C(=O)O1</smiles>

(e)

Figure 1. Structures of ochratoxin A (OTA) (a), ochratoxin B (OTB) (b), ochratoxin C (OTC) (c), ochratoxin $\alpha(\mathrm{OT} \alpha)(\mathbf{d})$ and ochratoxin $\beta(\mathrm{OT} \beta)(\mathbf{e})$.

Immunosensors have generated high expectations of providing fast and highly sensitive detection of food contaminants. In a recent study, two indirect competitive enzyme-linked immunosorbent assay (ELISA) strategies were used for the development of electrochemical immunosensors based on different OTA immobilization techniques for the detection of OTA in wine [32]. Immunosensors based on the immobilization of avidin/biotin-OTA conjugate seemed to have enhanced performance characteristics compared to those based on the adsorption of bovine serum albumin (BSA)-OTA conjugate on screen-printed electrode's (SPE) surface. Monoclonal (MAb) antibodies (clone 5G9) exhibited at least one order of magnitude lower $\mathrm{IC}_{50}$ values than polyclonal (PAb) rabbit antibodies against OTA, while PAb gave better reproducibility. The performances of alkaline phosphatase (ALP)- and horseradish peroxidase (HRP)-labeled secondary antibodies were also evaluated by using 
differential pulse voltammetry (DPV) and chronoamperometry, respectively (CA). Both conjugates led to similar results when working with OTA standard solutions in buffer, whereas in spiked wine samples, no significant effect was observed in HRP-labeled immunosensors ( $4 \%$ slope deviation), while electroactive interferences affected the working potential for ALP-labeled immunosensors $(25 \%$ slope deviation). Wine samples were prepared simply by adjusting $\mathrm{pH}$ to 7.2-7.4 with polyvinylpyrrolidone (PVP) for complex polyphenols, without any other clean-up or preconcentration steps. The detection limit (LOD) was set as $80 \%$ of antibody binding, and the HRP- and ALP-labeled immunosensors gave LOD values 0.7 and $0.3 \mu \mathrm{g} \mathrm{L} \mathrm{L}^{-1}$ respectively. No regeneration studies were mentioned in the published work.

A direct, competitive electrochemical immunosensor assay has also been developed for the quantitative determination of OTA using Pabs antibodies in Montepulciano d'Abruzzo red wine samples [33]. The assay was carried out on carbon-based SPEs through the electrochemical detection of 1-naphyhol, the product of the enzymatic reaction of 1-naphthyl phosphate with alkaline phosphatase (AP). Initially, a goat antibody (anti-rabbit IgG) was immobilized onto the SPE's surface followed by the addition of anti-OTA antibody (PAb) (anti-OTA rabbit IgG). Binding or competition studies were carried out by the addition of OTA-AP conjugate or conjugate/standard. The electrochemical responses were measured by DPV and showed improved analytical behavior compared to the classical spectrophotometric ELISA-based assay. After a simple clean-up step, the matrix effect seemed to have a negative effect on the detection limit (LOD) of the method. The immunosensor assay initially gave a LOD of $0.18 \mu \mathrm{g} \mathrm{L}^{-1}$ and a sensitivity (defined as $50 \%$ of the inhibition concentration) of $6.1 \pm 0.1 \mu \mathrm{g} \mathrm{L}{ }^{-1}$ for the standard solutions and $0.9 \mu \mathrm{g} \mathrm{L}{ }^{-1}$ and $1.5 \pm 4 \mu \mathrm{g} \mathrm{L}^{-1}$ for the wine samples, respectively. Recoveries obtained were between $70-118 \%$ with a relative standard deviation range $8.5-26 \%$.

In addition, another direct competitive magnetic bead-based immunosensor was developed for the determination of OTA in wine samples [34]. Streptavidin-covered magnetic beads $(1 \pm 0.5 \mu \mathrm{m}$ diameter) were functionalized with a Mab against OTA (clone 4F3g2, isotype IgG3/Kappa), and then left to incubate in a solution of tracer (OTA-HRP) and a range of OTA concentrations $\left(0.1\right.$ to $\left.10^{3} \mu \mathrm{g} \mathrm{L}^{-1}\right)$. After washing and separation steps assisted by a magnetic field, a volume of the dispersion was put on SPEs under a magnet and after the addition of the substrate, p-benzoquinone was detected by DPV. Wine samples were prepared simply by $\mathrm{pH}$ adjustment (7.5), with diluted $\mathrm{NaOH}$ and PVP. The immunosensor's responses after matrix effects studies by spiking red wines of "Campo de Borja" were compared with those obtained by HPLC coupled to a fluorescent detector (HPLC-FLD). The OTA levels in two red wine samples after HPLC-FLD analysis ranged from about $2.7 \times 10^{-2}-3.3 \times 10^{-2} \mu \mathrm{g} \mathrm{L}^{-1}$ whereas the immunosensor's LOD was less than $0.11 \pm 0.01 \mu \mathrm{g} \mathrm{L}^{-1}$ in both wine samples (the maximum permitted content of OTA by the European Union is $<2 \mu \mathrm{g} \mathrm{L}^{-1}$ ).

In another work, an integrated lab-on-a-chip system that conjugates an indirect competitive enzyme-linked immunosorbent assay strategy was developed in polydimethylsiloxane (PDMS) microfluidics with integrated microfabricated silicon photodiodes for chemiluminescence-based OTA detection in beer and wine [35]. A two-channel U-shaped microfluidic device with immobilized OTA-BSA was developed to perform analysis of a reference solution and an OTA-spiked solution (prepared by liquid-liquid extraction) simultaneously. The OTA molecules in solution compete with the immobilized OTA molecules in the microchannel (via adsorption of OTA-BSA) for limited rabbit anti-OTA binding sites. The solutions under analysis incubated with the anti-OTA prior to the insertion in the microchannel. A secondary HRP labeled anti-rabbit $\operatorname{IgG}$ that reacted with luminol was used for the optical amplification of the signal. This set up proved to efficiently reduce measurement errors and improve the LOD values of OTA one order of magnitude in beer and red wine extracts. The LOD obtained for beer extracts was up to $0.073 \mu \mathrm{g} \mathrm{L} \mathrm{L}^{-1}$, whereas for red wine extracts a higher LOD of $28 \mu \mathrm{g} \mathrm{L}^{-1}$ was obtained, indicating a clear influence of the sample matrix. A small sample volume was used for each assay $(10 \mu \mathrm{L})$ and the time from the injection of the OTA-BSA solution in the microfluidic system to the ELISA integrated detection was about $45 \mathrm{~min}$. 
An optical immunosensor for label-free detection of OTA in beer samples has been proposed by Pagkali et al. [36]. The biosensor consisted of an array of ten monolithically integrated Mach-Zehnder interferometers (MZIs) along with their respective broad-band silicon light sources on the same $\mathrm{Si}$ chip. The chip was transformed to a biosensor by functionalizing the MZIs sensing arms with an OTA-ovalbumin conjugate. OTA determination was performed by introducing, into the chip, mixtures of calibrators or samples with mouse anti-OTA MAb following an additional reaction step with a secondary goat anti-mouse antibody conjugated with HRP that increased the effective refractive index and enhanced the sensor's response. An external miniaturized spectrometer continuously recorded the transmission spectra of each interferometer, while spectral shifts obtained were transformed to phase shifts through Discrete Fourier Transform. The assay exhibited a LOD of $2 \mu \mathrm{g} \mathrm{L}^{-1}$ and a linear range between 4-100 $\mathrm{g} \mathrm{L}^{-1}$ in beer samples of different types (lager, pilsner, ale, dark), while recoveries ranged from $90.6-116 \%$. The results obtained with the sensor using OTA-spiked beer samples were satisfying when compared to those obtained by a commercial ELISA assay. As a mean to suppress the analysis cost, the potential of regeneration and re-use of biofunctionalized sensor chips was investigated. Thus, regeneration with $0.1 \mathrm{M} \mathrm{HCl}$ for $3 \mathrm{~min}$ removed completely the bound antibody molecules from the chip surface.

Biosensors with quartz crystal microbalance (QCM)-based readout are gaining popularity in the detection of chemicals and contaminants since they represent noninvasive tools for online monitoring and quantification of molecular interactions on solid surfaces [37]. A sensor based on a gold-coated QCM with dissipation monitoring (QCM-D) and immobilized polyclonal rabbit antibodies against OTA was developed for rapid and sensitive detection in red wine [38]. Thus, the device was capable of simultaneously measuring frequency $(\Delta \mathrm{f})$ and dissipation $(\Delta \mathrm{D})$ changes and providing detailed information about the mechanical and viscoelastic properties of the biofilm. The enhancement of the QCM-D signal was obtained by applying goat anti-rabbit secondary antibodies conjugated with gold nanoparticles (AuNPs). A linear range of $0.2-40 \mu \mathrm{g} \mathrm{L}^{-1}$ has been achieved with a LOD value of $0.16 \mu \mathrm{g} \mathrm{L} \mathrm{L}^{-1}$. Furthermore, no matrix effects or associated non-specific interactions with the sensor surface were observed due to a pre-treatment of the wine with the addition of $3 \%$ poly(vinylpyrrolidone) (PVP), whereas the sensor was regenerated after 10 min incubation in glycine buffer.

Electrochemical impedance spectroscopy (EIS) has also proved to be an effective method for monitoring the interfacial properties of the biochemical process and binding events occurring on the electrode's surface e.g., antigen-antibodies conjugation [39,40]. An impedimetric immunosensor for the fast determination of OTA in red wine samples was developed by using instant catalyst-promoted precipitation amplification process [41]. Polyclonal anti-OTA antibody (PAb) and amine-terminated dendrimer (PAMAM) were immobilized on the graphene oxide nanosheets (anti-OTA-GO-PAMAM- $\mathrm{Mn}^{2+}$ ) through a covalent reaction, whereas the surface of a glassy carbon electrode was modified with an OTA-BSA conjugate. Then, a competitive immunoassay was implemented between the analyte and the OTA-BSA on the electrode's surface for the anti-OTA $\mathrm{PAb}$ on the graphene oxide nanosheets labels. The anti-OTA-GO-PAMAM- $\mathrm{Mn}^{2+}$ were captured onto the electrode's surface, inducing the in situ formation of $\mathrm{MnO}_{2}$ via classical redox reaction between $\mathrm{Mn}^{2+}$ and $\mathrm{KMnO}_{4}$. Experimental results indicated that the generated $\mathrm{MnO}_{2}$ nanoparticles on the PAMAM-GO modified electrode could catalyze the 4-chloro-1-naphthol (4-CN) oxidation without the aid of $\mathrm{H}_{2} \mathrm{O}_{2}$ substrate and produce an insoluble precipitation on the electrode that changed its conductivity. Under optimal conditions, the impedimetric immunosensor displayed a wide dynamic working range between $10^{-4} \mu \mathrm{g} \mathrm{L}^{-1}$ and $30 \mu \mathrm{g} \mathrm{L}^{-1}$ and the LOD of the assay was $5.5 \times 10^{-5} \mu \mathrm{g} \mathrm{L}{ }^{-1}$. Based on these results, the combined, dual-approach immunosensor performed in a manner far superior to known immunoassays, at least as much as sensitivity of detection is concerned. Cross-reactivity studies revealed no significant changes by the presence of other mycotoxins and the recoveries from spiked red wine samples were found to vary from $96.8 \%$ to $106.5 \%$ confirming satisfactory accuracy of the assay. 
Recently, several aptamer-based biosensors (aptasensors) for OTA detection have been reported. A label-free aptamer-based assay for the highly sensitive and specific detection of OTA in Chinese liquor (Mao-tai) was developed [42]. The cationic polymer poly-diallyldimethylammonium chloride (PDDA) was used as a mediator for the aggregation of gold nanoparticles (AuNPs), whereas the OTA aptamer (5'-CTGGGAGGGAGGGAGGGATCGGGTGTGGGTGGCGTAAAGGGAGCATCGGACACCCG

ATCCC- $3^{\prime}$ ) oligonucleotide was used as a recognition element for the colorimetric detection of OTA. The reaction solution's color changes (from red to blue in the presence of OTA) were quantified by spectroscopic quantitative analysis at $520 \mathrm{~nm}$. The LOD obtained by the colorimetric assay in $1 \%$ liquor was $9 \times 10^{-3} \mu \mathrm{g} \mathrm{L}^{-1}$ with high selectivity against other interfering toxins, while the entire assay was completed in less than $30 \mathrm{~min}$.

Another simple and sensitive aptamer-based colorimetric method for the detection of OTA by using AuNPs has been developed by Yin et al. [43]. The biosensor used a 36-mer aptamer (5'-GATCGGGTGTGGGTGGCGTAAAGGGACATCGGACA-3') as bio-recognition element and unmodified AuNPs as probes. In the absence of OTA, the free aptamer was adsorbed onto the AuNPs surface, preventing their aggregation even with high concentrations of salt. The specific recognition of aptamers with OTA induced aggregation of AuNPs and the color turned from red to blue. The linear range was between 32-1024 $\mu \mathrm{g} \mathrm{L}^{-1}$ and the LOD value obtained was $20 \mu \mathrm{g} \mathrm{L}^{-1}$. The colorimetric assay also exhibited high selectivity in the presence of other mycotoxins. Meanwhile, this strategy was further used to determine the concentrations of OTA in white wine samples with recovery rates ranging from $100.8-112.5 \%$.

A portable aptasensor for OTA quantification using a structure-switching aptamer (biotin-AAAAAAGATCGGGTGTGGGTGGCGTAAAGGGAGCATCGGACA) and a commercially available personal glucometer (PGM) was proposed in a recent study, as an affordable portable device for home or field use [44]. The proposed system was based on the direct immobilization of the OTA aptamer onto magnetic beads (MBs) through a streptavidin-biotin reaction without causing any loss of switching activity. Initially, invertase-labeled competitor DNA (partly complementary to the aptamer) was hybridized with the aptamer to form a competitor DNA-aptamer-MBs complex. The addition of OTA triggered the transformation of the aptamer-competitor DNA duplex to the aptamer-OTA complex and released invertase. The released invertase catalyzed sucrose hydrolysis to glucose, which was measured by the PGM. The OTA concentration was proportional to glucose concentration. After optimization of the length and concentration of the competitor DNA the highest structure-switching activity of the aptamer on the MBs was obtained with the use of competitor-11 nt-OTA aptamer-MBs in order to improve the detection performance of OTA aptasensor. The optimal $\mathrm{pH}$ for sucrose hydrolysis to glucose was also determined. Under optimal conditions, the LOD in $2 \%$ red wine was $3.6 \mu \mathrm{g} \mathrm{L}^{-1}$ and the aptasensor showed considerable selectivity even in the presence of aflatoxins B1 and B2. 
Additionally, an impedimetric DNA aptamer biosensor onto a gold electrode's surface has also been reported [45]. EIS has been used for the determination of the charge transfer resistance $\left(\mathrm{R}_{\mathrm{ct}}\right)$ onto a gold electrode's surface, where thiolated DNA OTA aptamers of different configurations have been immobilized by chemisorption. The redox probe $\left[\mathrm{Fe}(\mathrm{CN})_{6}\right]^{-3 /-4}$ amplified the affinity interactions on the electrode's surface after the addition of OTA. The increase of the OTA concentrations caused an increase in $\mathrm{R}_{\mathrm{ct}}$. The LOD values obtained, ranging from $4.8 \times 10^{-2}$ to $0.16 \mu \mathrm{g} \mathrm{L}^{-1}$ depended on the aptamers' configuration. The sensor was regenerable at least up to 10 times and after validation studies in red wine samples the recovery ranged from $78-91 \%$.

Furthermore, many fluorescence-detection devices based on color models have been developed in order to be utilized as alternative OTA detection methods in beverages by avoiding extensive pretreatment steps. In a recent study, a portable and low-cost fluorescence setup has been used to quantify the concentration of OTA in beer and wine samples using an in-house developed system and different color models [46]. Since it has already been reported that OTA is naturally fluorescent [47], the researchers used an ultraviolet light at $365 \mathrm{~nm}$ in order to excite the samples, and a Complementary Metal Oxide Semiconductor (CMOS) sensor to photograph the OTA under excitation conditions, controlled by an executable interface designed in MATLAB. For each OTA concentration, the coordinates obtained with respect to each model color were plotted to quantify the mycotoxin present in the sample. This three-color model (red, green, blue: RGB) presented a proportional relation to the evaluated concentrations without employing any extraction procedure. The LOD and quantification limit (LOQ) are $2 \times 10^{-3} \mu \mathrm{g} \mathrm{L}^{-1}$ and $5 \times 10^{-3} \mu \mathrm{g} \mathrm{L}^{-1}$, respectively, in beer and wine samples.

Another innovative approach for the quantification of OTA concentrations in beer samples, by using the smartphone as a fluorescence-measuring device, was described by Bueno et al. [48]. When the sample was excited with ultraviolet (UV) light, the fluorescence from the sample passed through a lens to the smartphone camera and was sent by wireless connection to a personal computer. There, the fluorescence image data from the smartphone camera was analyzed and the images were represented in their RGB components. No fluorescence was observed for blank solutions, whereas the intensity of the blue fluorescence of the samples was directly proportional to the OTA concentrations. A graphical user interface (GUI) in MATLAB was also developed for image processing. The linear range of the developed system was between 2-20 $\mu \mathrm{g} \mathrm{L}^{-1}$ and the LOD value was $2 \mu \mathrm{g} \mathrm{L}^{-1}$, which is comparable with similar commercial equipment that also employs a smartphone as a power source.

A comparative summary of the available biosensors for ochratoxin A detection in wine and beer samples is presented in Table 1. 
Table 1. Comparative overview of current biosensor technologies and/or concepts for the detection of OTA in wine and beer samples.

\begin{tabular}{|c|c|c|c|c|c|c|c|c|}
\hline Biorecognition Element & Assay Concept & $\begin{array}{l}\text { Sensitivity }\left(\operatorname{LOD} \mu \mathrm{g} \mathrm{L}^{-1}\right) \\
\text { European } M R L=2 \mu g L^{-1}\end{array}$ & Selectivity & Speed & $\begin{array}{c}\text { Quantitative } \\
\text { Determination }\end{array}$ & $\begin{array}{c}\text { Sample } \\
\text { Pretreatment } \\
\text { Required }\end{array}$ & $\begin{array}{c}\text { Ease of } \\
\text { Handling }\end{array}$ & References \\
\hline Antibody (polyclonal and monoclonal) & Electrochemical & $0.7 \& 0.3$ & Yes & $<1 \mathrm{~h}$ & Yes & Yes & Yes & [32] \\
\hline Antibody (polyclonal) & Electrochemical & 1.5 & Yes & $>$ day & Yes & Yes & Yes & [33] \\
\hline Antibody (monoclonal) & Electrochemical & 0.11 & Yes & $>$ day & No & Yes & Yes & [34] \\
\hline Antibody (polyclonal) & Optical (Microfluidic) & $0.073-28$ & Yes & $>1 \mathrm{~h}$ & Yes & Yes & Yes & [35] \\
\hline Antibody (monoclonal) & Optical & 2 & $\mathrm{n} / \mathrm{a} *$ & $>1 \mathrm{~h}$ & Yes & Yes & Yes & [36] \\
\hline Antibody (polyclonal) & QCM-Dissipation monitoring & 0.16 & $\mathrm{n} / \mathrm{a}$ & $<1 \mathrm{~h}$ & Yes & Yes & Yes & [38] \\
\hline Antibody (polyclonal) & Electrochemical impedance spectroscopy & 0.000055 & Yes & $>1 \mathrm{~h}$ & Yes & Yes & Yes & [41] \\
\hline Aptamer & Optical (AuNPs) & 0.009 & Yes & $<1 \mathrm{~h}$ & Yes & Yes & Yes & [42] \\
\hline Aptamer & Optical (AuNPs) & 20 & Yes & $<1 \mathrm{~h}$ & Yes & $\mathrm{n} / \mathrm{a}$ & Yes & [43] \\
\hline Aptamer & PGM & 3.6 & Yes & $>1 \mathrm{~h}$ & Yes & Yes & Yes & [44] \\
\hline Aptamer & Electrochemical impedance spectroscopy & $0.048-0.16$ & Yes & $>1 \mathrm{~h}$ & Yes & $\mathrm{n} / \mathrm{a}$ & Yes & [45] \\
\hline - & Optical (CMOS) & 0.002 & $\mathrm{n} / \mathrm{a}$ & $<20 \mathrm{~min}$ & Yes & No & Yes & [47] \\
\hline - & Optical (Smartphone) & 2 & $\mathrm{n} / \mathrm{a}$ & $<20 \min$ & Yes & No & Yes & [48] \\
\hline
\end{tabular}




\section{Biosensors for the Detection of Haloanisoles in Wine and Beverages}

Haloanisoles, mainly 2,4,6-trichloanisole (2,4,6-TCA) and, to a lesser degree, 2,4,6-tribromoanisole (2,4,6-TBA) and the precursor compound 2,4,6-trichlorophenol (TCP) (Figure 2), are metabolites produced in cork following infection by fungi belonging to the genus Aspergillus, such as A. versicolor and A. oryzae. Among other fungal species able to convert 2,4,6-TCP to 2,4,6-TCA are Actinomyces sp., Cladosporium cladosporioides, Fusarium asiaticum and Talaromyces pinophilus [49]. Due to their high hydrophobicity, haloanisoles are readily soluble in wine and other alcoholic beverages, albeit in very small concentrations. Even so, they are responsible, as off-flavor compounds, for the so-called "cork taint", a moldy olfactory effect that is acutely associated with inferior beverage quality and possible carcinogenicity after long-term exposure [50-52]. The olfactory properties of TCA have been experimentally ascribed, at least in part, to the suppression of cyclic nucleotide-gated (CNG) channels in olfactory receptor cells (ORCs), leading to the reduced perception of odors [53]. More analytically, the membrane current of single ORCs, enzymatically derived from the olfactory epithelium of the newt (Cynops pyrrhogaster), was measured using a whole-cell patch-clamp set up and after loading cells with caged cAMP or $\mathrm{Ca}^{2+}$ with or w/o the addition of TCA. It was shown that even an extremely low TCA concentration (one aM, roughly containing just a single TCA molecule) is enough to significantly suppress CAMP-mediated transduction currents.<smiles>COc1c(Cl)cc(Cl)cc1Cl</smiles>

(a)<smiles>COc1c(Br)cc(Br)cc1Br</smiles>

(b)<smiles>Oc1c(Cl)cc(Cl)cc1Cl</smiles>

(c)

Figure 2. Structures of 2,4,6-trichloanisole (2,4,6-TCA) (a) and the structurally related/co-occuring 2,4,6-tribromoanisole (2,4,6-TBA) (b) and 2,4,6-trichlorophenol (TCP) (c).

Routine determination of 2,4,6-TCA in cork and wine is done either by sensorial or chromatographic methods [54]. The first approach is entirely subjective and exclusively qualitative, though very fast and inexpensive. Additional limitations of the sensorial evaluation relate to panelist fatigue, differing levels of sensitivity, professional experience and substrate influence [8]. For example, an increased alcohol content may reduce TCA volatility and, consequently, perception. Also, sensitivity of detection in white wines is reported to be double than in red ones, revealing a strong matrix effect. On the other hand, chromatography offers many capabilities, such as higher sensitivity and resolving power, as well as the capacity to determine co-occurring compounds. The current golden standard in TCA analytics is gas chromatography coupled with mass spectrometry (GC-MS) or with electron capture detector (GC- $\mu \mathrm{ECD}$ ), the latter approach being more suitable for quantification [55-57]. This is due to the fact that, as a chromatography separation method, GC-MS offers a larger number of theoretical plates, while ECD has been identified as the most selective detector for halogen-containing analytes. Irrespective of the configuration of the analytical set up, major drawbacks of the chromatographic approach relate to the requirement for considerable sample pretreatment and cork extract concentration in order to yield as much releasable TCA as possible 
from corks. A $24-\mathrm{h}$ extraction of cork in $12 \%$ aqueous-alcoholic solution or white wine of similar alcoholic strength is considered the acceptable protocol as defined by both ISO20752:2014(E) and OIV-MA-AS315-16 standards [58,59]. Beyond this considerably time-consuming step, additional sample processing (e.g., clean-up, halophenol derivatization) may be required. Techniques to improve the quantification of releasable TCA from cork stoppers include headspace solid-phase microextraction (HS-SPME) [60] and improved extraction methods with drastically reduced extraction time and solvent consumption, such as solid-phase microextraction (SPME) [61], supercritical-fluid extraction (SFE) [62], cloud-point extraction [63] and pressurized-liquid extraction (PLE) [64], with a dynamic extraction duration of 4-15 $\mathrm{min}$. An excellent review of current haloanisole determination methods is provided by Tarasov et al. [65]. Apart from the time required for sample pretreatment and the analysis itself (at least $30 \mathrm{~min}$ ), chromatographic methods are usually expensive and can be only applied in a dedicated laboratory, requiring considerable investment in sophisticated equipment and trained personnel.

From a strict point of view, there are very few reported approaches to biosensor-based detection of TCA and other haloanisoles and/or halophenols in cork, wine and other beverages. Related research has been focused on bioanalytical methods employing either antibodies, cells or their combination as biorecognition elements or non-invasive optical-detection principles.

The development of the first competitive immunoassay for TCA by Sanvicens et al. $[66,67]$ could be considered as the first step towards the establishment of a bioanalytical method in this specific area of application. This was achieved by raising female New Zealand white rabbit polyclonal antibodies against three immunizing haptens, with the best results $\left(\mathrm{IC}_{50}<10 \mu \mathrm{g} \mathrm{L}{ }^{-1}\right)$ derived from the hapten (hapten C) (Figure 3) better preserving the geometry of TCA, defined by the methoxy group and the two chlorine atoms in ortho, therefore ensuring the greatest exposure to the animal immune system. There were several issues regarding the efficiency of the immunoassay, in particular limited reproducibility (with a standard deviation of at least $22 \%$ between tests conducted on different days), deviation from the standard curve (the so-called Hook effect) and considerable lipophilicity ( $\log \mathrm{P}=4.11)$, which dictated limitations in the type of solvents (optimally DMSO or dioxane), detergents (minimum use of Tween 20) and labware material (less preferably plastic) used. The polyclonal antibody contained in antisera As76/C14-CONA $\left(\mathrm{pAb}_{76}\right)$ was identified as the optimum compromise between sensitivity of detection $\left(2.66+2.88 \mu \mathrm{g} \mathrm{L}^{-1}\right)$ and reproducibility $(106 \%)$ and thus was used in further studies. From a practical point of view, several additional parameters have been validated as possibly affecting the performance of the immunoassay, including, but not limited to, the number of freeze-thaw cycles (negative effect), the length of the incubation period (with an optimum time of $20 \mathrm{~min}$ ), $\mathrm{pH}$ (with an optimum range of 7.5-8.5) and matrix (in particular, white vs. red wine). In spite of these limitations, the immunoassay performed outstandingly in terms of selectivity (with minimum cross-reactivity by structurally related and co-occurring compounds such as di- and tetrachloroanisole and di- and tetrachlorophenol) and accuracy against standard solutions of the target compounds. The immunoassay was also validated with white and red wines analyzed with SPME-GC-MS to ensure the absence of TCA, i.e., only the matrix effect was investigated on the general performance of the assay. It was found that considerable interference was caused by the wine matrix, which was fivefold higher in red wines compared to white ones, thus necessitating the dilution of the sample. However, no validation of the method with commercial samples was carried out. Hence, the usefulness of the immunoassay approach should be viewed on the level of proof-of-concept. 
<smiles>O=C(O)Cc1cc(Cl)c(O)c(Cl)c1</smiles>

Figure 3. Structure of the immunizing TCA hapten C (modified from [66]).

The same PAb developed by Sanvicens et al. has been utilized in yet another, disruptive biosensor-based approach, originally developed by Varelas et al. [68]. In this case, cellular biorecognition elements with a highly selective response against TCA were created by the osmotic insertion of $\mathrm{PAb}_{76}$ into the membrane of immortalized hamster adult kidney (HaK) cells, immobilized in an alginate gel matrix. This approach was applied according to the concept of the technology of molecular identification through membrane engineering [69-71], whereas binding of the antigenic part of the target analyte on the membrane-bound antibody will cause a considerable, specific and readily measurable change of the engineered cell's membrane potential. In turn, this change can be measured with established electrophysiological techniques, in particular the practically applicable bioelectric recognition assay (BERA) [72-74], a method based on the measurement of the bioelectric properties of a cluster of cells, usually gel-immobilized. Under the experimental conditions applied in [68], a very low limit of detection (0.1 ppt) was achieved for TCA, a value that is lower than the human sensory threshold concentration. It was shown that the response of membrane-engineered cells to increasing TCA concentrations was partly due to the depletion of their intracellular $\mathrm{Ca}^{2+}$ stores, while the overall assay was completed in just five minutes. At the same time, a linear response of $\mathrm{pAb}_{76}$ antibody-engineered $\mathrm{HaK}$ cells was observed against TCA. On the other hand, non-engineered cells also responded to the target analyte, albeit in a non-linear fashion, possibly due to the direct binding of the lipophilic haloanisole molecules on the cell membrane. At a given, relatively high concentration of $10 \mathrm{ppm}$, no interference was observed between the detection of TCA and structurally related and / or co-occurring compounds such as 2,4,6-trichlorophenol (TCP), 2,4,6-tribromoanisole (TBA), 2,6-dichloroanisole (2,6-DCA), 2,3-DCA, 3,5-DCA and 2,3,4,5-tetrachloroanisole (TeCA). This novel approach has been validated in a double-blind trial against a series of white and red wines of Spanish origin (analyzed in parallel with SPME-GC-MS) in the framework of the FOODSCAN project (foodscan.net). A high correlation (93\%) was determined between the biosensor-based and chromatography analysis.

A considerable improvement of the BERA-based approach was reported by Apostolou et al. [75] who modified the protocol of Varelas et al. [68] by electroinserting (instead of osmotically handling) Monkey African green kidney (Vero) cells with the same antibody $\left(\mathrm{PAb}_{76}\right)$. In addition, cells were non-immobilized (i.e., in suspension) so that direct contact with the potential measuring electrode was established (Figure 4). The entire biosensor set-up was redesigned into a portable, essentially handheld screener (Figure 5). By using the modified system, it was able to directly detect TCA in cork detritus, without any sample extraction at all. Similarly, to the previous approach, ultra-rapid ( $3 \mathrm{~min}$ ) and sensitive $\left(2 \times 10^{-4} \mu \mathrm{g} \mathrm{L}^{-1}\right)$ detection was achieved. This innovative method was validated in a double-blind trial on a large number of cork samples. A very high correlation $\left(\mathrm{r}^{2}=0.9864\right)$ was observed between results obtained with the novel biosensor and standard chromatographic analysis performed in an independent, certified laboratory according to ISO Standard 20752:2007 and OIV'sResolution 296/2009. Consequently, this achievement could represent a disruptive change in cork-quality screening. However, a possible limitation of the BERA-based approaches is the rather limited range of detectable TCA concentrations (up to $0.014 \mu \mathrm{g} \mathrm{L}^{-1}$ ), since higher concentrations would 
act as toxicants to the cellular biorecognition elements. Quite recently, Tarasov et al. [65] published a critical review of the merits and possible restrictions of the applicability of BERA-based biosensor approaches for screening corks for haloanisoles. They emphasized on the potential of the method as an outstanding tool for the express, sensitive and low-cost on-site screening of the cork material, even though not yet suitable for the derivation of quantitative results. Beyond membrane-engineered cells with designed selectivity, cellular biorecognition elements having a natural response against haloanisols (e.g., cells expressing olfactory receptors [53]) could also be used as part of an improved bioelectric recognition biosensor for TCA determination. That said, the broader use of cell-based biosensors faces additional challenges, for instance cell handling and storage, which could render problematic their use in automated screening system.

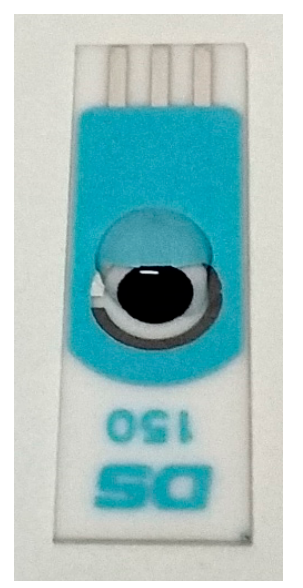

Figure 4. Direct contact between the cell suspension of pAb76-membrane-engineered Vero cells and the screen-printed working electrode.

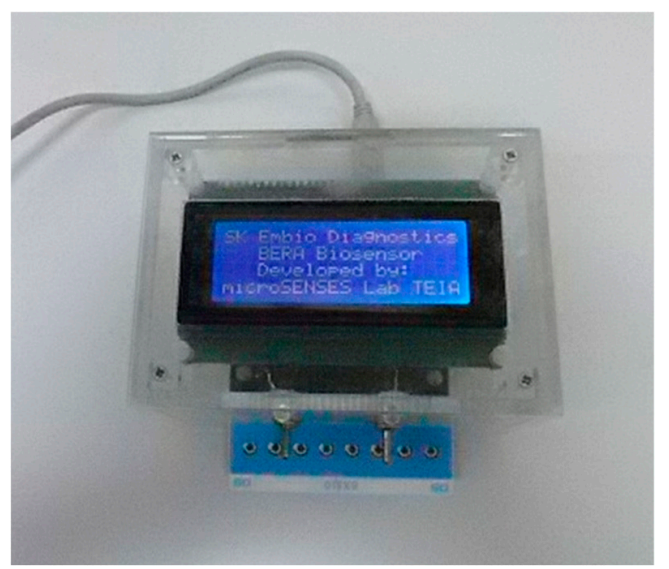

Figure 5. The handheld TCA screener with the disposable eight-channel electrode strip attached to the main measuring unit. 
Direct electrochemical detection of TCA is another methodological approach with promising perspectives for practical application, at least in terms of speed and, possibly, reduced requirements for sample pretreatment. Moore et al. [76] prepared immunoelectrodes by adding a drop of $5 \mu \mathrm{L}$ of $7.5 \mu \mathrm{g} \mathrm{mL}{ }^{-1}$ of $\mathrm{pAb}_{76}$ [66] onto the surface of a carbon screen-printed working electrode. Following incubation (one hour at room temperature), washing away of unbound IgG and blocking of the electrode surface, the electrodes were immersed in $150 \mu \mathrm{L}$ of a 1:1 mixture of TCA hapten-AP $(3.5 \mu \mathrm{g} / \mathrm{mL})$ and the TCA analyte. Amperometry experiments were carried out at $+300 \mathrm{mV}$ vs. $\mathrm{Ag} / \mathrm{AgCl}$. Reproducible determination of TCA was possible only in a buffer matrix with a LOD of $0.029 \mu \mathrm{g} \mathrm{L}^{-1}$, (considerably higher than the set limit for rejection). In addition, it was not possible to apply the method in wine samples, since the wine matrix inhibited the competition reaction. An electrochemical displacement immunoassay for TCA was reported by Duarte et al. [77], based on the use of the sub-optimum antigen 3-chloro-2-methylphenoxyacetic acid (H3) which was labeled by conjugation to HRP. Binding of the H3-HPR conjugate to a commercial anti-TCA MAb produces a signal which is lost upon displacement of the sub-optimum antigen by TCA. Immunoelectrodes were prepared first by immersion of gold electrodes in 3-mercaptopropionic acid to facilitate the formation of thiol-based self-assembled monolayers (SAMs), then acquiring a copper monolayer which was deposited on gold by means of underpotential deposition (UDP) via reductive linear-sweep voltammetry, a process creating more reproducible copper surfaces. Copper-coated electrodes were finally immersed in H3-HPR (30 min). Electrochemical measurements of the concentration of the $\mathrm{H}_{2} \mathrm{O}_{2}$ substrate were carried out at $+100 \mathrm{mV}$ vs. $\mathrm{Ag} / \mathrm{AgCl}$. In the framework of this proof-of-concept study, an LOD of $200 \mu \mathrm{g} \mathrm{L}^{-1}$ of TCA and good discrimination against the interferant TCP were achieved. Finally, Peres et al. [78,79] reported the use of cyclic voltammetry (CV) for determination of TCA in aqueous cork extracts, resulting from the immersion of cork planks in boiling water (60 min), which is a standard component of commercial cork processing. Tetrabutylammonium perchlorate (TBAP, $0.1 \mathrm{M}$ ) was used as the supporting electrolyte in order to increase current intensity. CV was performed in a mixture of acetonitrile:water $(3: 2 v / v)$ with a silver working electrode. Two cycles were performed, being the cyclic voltammograms recorded from -2.0 to $1.6 \mathrm{~V}$, at a potential scan rate of $100 \mathrm{mV} / \mathrm{s}$. with fairly low detection ( $\mathrm{LOD}=3.17 \times 10^{-4} \pm 0.01 \mu \mathrm{g} \mathrm{L}^{-1}$ ) and quantification limits $\left(\mathrm{LOQ}=9.57 \times 10^{-4} \pm 0.05 \mu \mathrm{g} \mathrm{L}^{-1}\right)$, and intra-day repeatability lower than $3 \%$. Although a concentration-dependent biosensor response was observed up to $5.2 \times 10^{-2} \mu \mathrm{g} \mathrm{L}^{-1}$ of TCA, a linear pattern could be established only in the narrow range of $1.2 \times 10^{-2}-5 \times 10^{-2} \mu \mathrm{g} \mathrm{L}^{-1}$. On the other hand, good correlation was observed between the CV-based approach and results obtained with GC-MS as a reference method, according to the methodology described in ISO 20752:2007 Standard and in OIV's Resolution 296/2009, even though no double blind trial was carried out in an independent laboratory. 
An entirely different analytical concept was tested by Garcia et al. [80] who applied attenuated total reflection infrared spectroscopy (ATR-IR), combined with multivariate statistics linear analysis (LDA), for the direct detection of TCA in corks. Their methodology was based on the measurement of three groups of strong bands in the cork IR spectrum, namely at 2900-3200, 1600-1370 and $\sim 1000-600 \mathrm{~cm}^{-1}$. The occurrence of TCA was identified mainly by the presence of two new bands at $1417 \mathrm{~cm}^{-1}$ and $1314 \mathrm{~cm}^{-1}$, corresponding to respective vibrational shifts of the $C=C$ and $C C$ bonds of the TCA structure, as well as an increased relative intensity of the spectral region between $950 \mathrm{~cm}^{-1}$ and $800 \mathrm{~cm}^{-1}$ ( $\mathrm{CCl}$ bonds). In spite of the preliminary, proof-of-concept and strictly qualitative character of this method, its non-invasive character renders ATR-IR an attractive perspective for automated, high throughput, in-line cork screening. One possible limitation to the broader acceptance of this approach is its more restrictive nature leading to a higher percentage of cork rejection compared to other methods.

A comparative summary of the available biosensors for TCA detection is presented in the following table (Table 2). It must be emphasized that the majority of reported biosensor-based approaches are still in the stage of proof-of-concept, with limited testing on real samples. Even methods that have been properly validated with reference chromatographical methods (such as the BERA-based systems) have not yet been widely used in order to fully investigate the scope and limits of their practical application. Therefore, among the top priorities for future biosensor development for the detection of haloanisoles is the improvement of quantitative response, portability and minimizing requirements for sample extraction and concentration methodologies. However, what is even more important, is the efficient compatibility of innovative biosensor systems with the already used automated instrumentation for cork quality screening, for the identification of defects in the cork structure. Based on our profound knowledge on the TCA analytical technologies and the related business needs, we strongly believe that the time is ripe for a major upgrade in the cork industry. However, progress in the amelioration of the widely used routine chromatographic analytical methods should not be disregarded; in contrast, direct, often non-destructive [81], solvent-free cork analysis methods [82-84] based on analyzing gases emitted from corks (usually heated by means of microwave radiation $[57,85]$ or supercritical fluid extraction [63]) in combination with miniaturization of chromatography equipment can offer high recoveries and good reproducibility, even at the expense of speed and full portability. 
Table 2. Comparative overview of current biosensor technologies and/or concepts for the detection of 2,4,6-TCA in cork, wine and water samples.

\begin{tabular}{|c|c|c|c|c|c|c|c|c|}
\hline Biorecognition Element & Assay Concept & Sensitivity (LOD $\left.\mu \mathrm{g} \mathrm{L}^{-1}\right)$ & Selectivity & Speed & $\begin{array}{c}\text { Quantitative } \\
\text { Determination }\end{array}$ & $\begin{array}{l}\text { Sample Pretreatment } \\
\text { Required }\end{array}$ & $\begin{array}{c}\text { Ease of } \\
\text { Handling }\end{array}$ & References \\
\hline Antibody (polyclonal) & Optical & $2.66 \& 2.88$ & Yes & $>1 \mathrm{~d}$ & Yes & Yes & Yes & {$[67,68]$} \\
\hline Antibody (polyclonal) & Electrochemical & 0.029 & Yes & $>1 \mathrm{~d}$ & No & Yes & Yes & [76] \\
\hline Antibody (monoclonal) & Electrochemical & 200 & Yes & $>1 \mathrm{~h}$ & Yes & Yes & Yes & [77] \\
\hline \multirow{3}{*}{$\begin{array}{c}\text { Cell (membrane engineered } \\
\text { with antibodies) }\end{array}$} & Bioelectric & 0.001 & Yes & $<1 \mathrm{~h}$ & Yes & No & Yes & {$[68,75]$} \\
\hline & $\begin{array}{c}\text { Electrochemical } \\
\text { Optical (attenuated total }\end{array}$ & 0.00031 & Yes & $<1 \mathrm{~h}$ & Yes & Yes & Yes & {$[78,79]$} \\
\hline & $\begin{array}{l}\text { reflection infrared } \\
\text { spectroscopy (ATR-IR)) }\end{array}$ & $\mathrm{n} / \mathrm{a}^{*}$ & $\mathrm{n} / \mathrm{a}$ & $<1 \mathrm{~h}$ & No & No & Yes & {$[80]$} \\
\hline
\end{tabular}

*n/a: Not available. 


\section{Conclusions}

The global market of food analysis demands reliable, inexpensive methods for determining mycotoxin and haloanisole residues in beverages $[5,23,56]$. Biosensors are ideal candidates for evaluating beverage quality in terms of presence of contaminants. Emerging technologies have been developed for the assessment of numerous target compounds in various commodities. Biosensors would introduce a revolutionary technology as alternatives to conventional analytical methods (e.g., HPLC, GC and MS/MS) due to the various advantages they possess. They hold the promise to perform high-speed measurements, (from minutes to a few hours), they have high specificity and sensitivity (in nanomolar and sometimes femtomolar ranges), and can be automated (at least on a conceptual basis), giving the potential for real-time and on-line measurements along the production chain $[12,14]$. It should be mentioned, however, that this estimation is based on published data from original research mainly conducted in a controlled laboratory environment; the real applicability of said novel biosensor approaches and technologies should be validated on actual samples and, more importantly, in an end-user, commercial setting.

As indicated by the references in Table 1, different types of multiplexed sensors for the detection of ochratoxin A in beverages have been rapidly developed during the past 5 years. Immunosensors using enzymatic labels (e.g., HRP, AP) tend to be sensitive because of the potential for significant amplification provided by the enzyme. They also tend to use commonly available optical or electrochemical readers that are relatively inexpensive [32-36]. The downside to these immunoassays is that most require additional steps (e.g., washing, adding substrate and/or mediator) that are avoidable with certain other formats. These steps add time, and this is one reason for the continued development of non-enzymatic labels and label-free devices in order to achieve portability of the devices [47,48]. These disadvantages can be also overcome with the use of aptamer nucleotide sequences and AuNPs labels that are able to discriminate between various toxin categories [42-45]. However, for the time being, such formats tend to require expensive, laboratory-based equipment that requires significant technical training to operate.

In the case of haloanisoles, in particular TCA, the majority of reported biosensor-based approaches are still at the stage of proof-of-concept and require considerable validation and, probably, optimization before being applicable for routine use as screening tools. Based on available research results, the wine matrix may present a considerable interferant for immunoassay-based methods [61]. With the exception of cell-based assays, biosensors for TCA detection need to be improved in terms of sensitivity. On the other hand, they seem to promise superior speed, cost-efficiency and ease of handling compared to conventional methods of analysis. These factors may be of commercial significance considering the scale of analytical demand by the respective industry.

Further detailed research is needed for the commercialization of biosensor technology. Biosensors could be improved by the development of new bio-recognition elements. Recent advances in bioinformatics technology could enhance knowledge on the biocomponent/transducer interface and contribute to the design of new bio-recognition elements. Moreover, the evolution of synthetic biology that enables us to modify the genetic code of biological systems and to reprogram them to perform new tasks will help us to overcome challenges such as lowering the detection limits, increasing sensitivity, and lowering production cost. In addition, synthetic materials, genetically-engineered molecules, aptamers and artificial membranes have recently received great attention as novel biosensing materials with improved performance and/or additional functions $[15,16]$. Poor stability of biological molecules could be overcome by developing artificial molecular recognition elements with the desired selectivity and sensitivity towards various compounds. Nonetheless, information and communication technology in biosensing applications could provide the construction of biosensor-embedded systems for the integration of biological components with transducers, microfluidics, and network systems [48]. Automated systems and wireless technologies can be small, inexpensive and sustainable in energy use, reducing costs and significantly improving food production and quality. 
Author Contributions: Both authors contributed equally to this work. S.M. wrote the first part of the manuscript concerning biosensors that detect ochratoxin A in beverages and S.K. wrote about biosensors detecting halonisoles in wine and other beverages. Both authors discussed the results and commented on the manuscript at all stages.

Conflicts of Interest: The authors declare no conflict of interest.

\section{References}

1. Bennet, J.; Klich, M. Mycotoxins. Clin. Microbiol. Rev. 2003, 16, 497-516. [CrossRef]

2. Venâncio, A.; Paterson, R. The challenge of mycotoxins. In Food Safety-A Practical and Case Study Approach; McElhatton, A., Marshall, R., Eds.; Springer: Heidelberg, Germany, 2007; Volume 1, pp. 24-47, ISBN 978-0-387-33957-3.

3. Bhat, R.; Rai, R.; Karim, A. Mycotoxins in food and feed: Present status and future concerns. Compr. Rev. Food Sci. Food Saf. 2010, 9, 57-81. [CrossRef]

4. European Food Safety Authority (EFSA). Aflatoxins (sum of B1, B2, G1, G2) in cereals and cereal-derived food products. EFSA Support. Publ. 2013, 406, 1-11. [CrossRef]

5. Milićević, D.; Škrinjar, M.; Baltić, T. Real and perceived risks for mycotoxin contamination in foods and feeds: Challenges for food safety control. Toxins 2010, 2, 572-592. [CrossRef] [PubMed]

6. Richard, J. Some major mycotoxins and their mycotoxicoses-An overview. Int. J. Food Microbiol. 2007, 119, 3-10. [CrossRef] [PubMed]

7. European Food Safety Authority (EFSA). Evaluation of the increase of risk for public health related to a possible temporary derogation from the maximum level of deoxynivalenol, zearalenone and fumonisins for maize and maize products. EFSA J. 2014, 12, 51-54. [CrossRef]

8. Cravero, M.C.; Bonello, F.; Pazo Alvarez del Carmen, M.; Tsolakis, C.; Borsa, D. The sensory evaluation of 2,4,6-trichloroanisole in wines. J. Inst. Brew. 2015, 121, 411-417. [CrossRef]

9. Berthiller, F.; Dall'Asta, C.; Schuhmacher, R.; Lemmens, M.; Adam, G.; Krska, R. Masked mycotoxins: Determination of a deoxynivalenol glucoside in artificially and naturally contaminated wheat by liquid chromatography-tandem mass spectrometry. J. Agric. Food Chem. 2005, 53, 3421-3425. [CrossRef] [PubMed]

10. Krska, R.; Baumgartner, S.; Josephs, R. The state-of-the-art in the analysis of type-A and -B trichothecene mycotoxins in cereals. Fresenius J. Anal. Chem. 2001, 371, 285-299. [CrossRef] [PubMed]

11. Abdallah, M.; Krska, R.; Sulyok, M. Mycotoxin Contamination in Sugarcane Grass and Juice: First Report on Detection of Multiple Mycotoxins and Exposure Assessment for Aflatoxins B1 and G1 in Humans. Toxins 2016, 8, 343. [CrossRef] [PubMed]

12. Scognamiglio, V.; Arduini, F.; Palleschi, G.; Rea, G. Bio sensing technology for sustainable food safety. Trends Anal. Chem. 2014, 62, 1-10. [CrossRef]

13. Thevenot, D.; Toth, K.; Durst, R.; Wilson, G. Electrochemical biosensors: Recommended definitions and classification. Anal. Lett. 2001, 34, 635-659. [CrossRef]

14. Omrani, N.M.; Hayat, A.; Korri-Youssoufi, H.; Marty, J.L. Electrochemical biosensors for food security: Mycotoxins detection. In Biosensors for Security and Bioterrorism Applications; Nikolelis, D., Nikoleli, G.P., Eds.; Springer International Publishing: Cham, Switzerland, 2016; pp. 469-490, ISBN 978-3-319-28926-7.

15. Bazin, I.; Tria, S.; Hayat, A.; Marty, J. New biorecognition molecules in biosensors for the detection of toxins. Biosens. Bioelectron. 2017, 87, 285-298. [CrossRef] [PubMed]

16. Choi, S.; Chang, H.; Lee, N.; Chun, H. A Surface Plasmon Resonance Sensor for the Detection of Deoxynivalenol Using a Molecularly Imprinted Polymer. Sensors 2011, 11, 8654-8664. [CrossRef] [PubMed]

17. Buerk, D. Biosensors: Theory and Applications; CRC Press: Lancaster, PA, USA, 1995; pp. 6-15, ISBN 9780877629757.

18. Koyun, A.; Ahlatcığlu, E.; İpek, Y. Biosensors and Their Principles. In A Roadmap of Biomedical Engineers and Milestones; Kara, S., Ed.; InTech: Vienna, Austria, 2012, ISBN 978-953-51-0609-8.

19. Bueno, D.; Istamboulie, G.; Muñoz, R.; Marty, J. Determination of Mycotoxins in Food: A Review of Bioanalytical to Analytical Methods. Appl. Spectrosc. Rev. 2015, 50, 728-774. [CrossRef]

20. International Agency for Research on Cancer (IARC). Ochratoxin A. In IARC Monographs on the Evaluation of Carcinogenic Risks to Humans: Some Naturally Occurring Substances, Food Items and Constituents, Heterocyclic Aromatic Amines and Mycotoxins; World Health Organization: Geneva, Switzerland, 1993; Volume 56, p. 489, ISBN 9789283212560. 
21. Drunday, V.; Pacin, A. Occurrence of Ochratoxin A in coffee beans, ground roasted coffee and soluble coffee and method validation. Food Control 2013, 30, 675-678. [CrossRef]

22. Batista, L.R.; Chalfoun, S.M.; Silva, C.F.; Cirillo, M.; Varga, E.A.; Schwan, R.F. Ochratoxin A in coffee beans (Coffea arabica L.) processed by dry and wet methods. Food Control 2009, 20, 784-790. [CrossRef]

23. Kuiper-Goodman, T.; Hilts, C.; Billiard, S.; Kiparissis, Y.; Richard, I.; Hayward, S. Health risk assessment of ochratoxin A for all age-sex strata in a market economy. Food Addit. Contam. Part A Chem. Anal. Control Expo Risk Assess 2010, 27, 212-240. [CrossRef] [PubMed]

24. Peters, J.; van Dam, R.; van Doorn, R.; Katerere, D.; Berthiller, F.; Nielen, M. Mycotoxin profiling of 1000 beer samples with a special focus on craft beer. PLOS ONE 2017, 12, e0185887. [CrossRef] [PubMed]

25. Inoue, T.; Nagatomi, Y.; Uyama, A.; Mochizuki, N. Fate of mycotoxins during beer brewing and fermentation. Biosci. Biotechnol. Biochem. 2013, 77, 1410-1415. [CrossRef] [PubMed]

26. Anli, R.; Vural, N.; Bayram, M. Removal of Ochratoxin A (OTA) from Naturally Contaminated Wines During the Vinification Process. J. Inst. Brew. 2011, 117, 456-461. [CrossRef]

27. Dachery, B.; Manfroi, V.; Berleze, K.; Welke, J. Occurrence of ochratoxin A in grapes, juices and wines and risk assessment related to this mycotoxin exposure. Cienc. Rural 2016, 46, 176-183. [CrossRef]

28. Bolton, S.; Mitchell, T.; Brannen, P.; Glenn, A. Assessment of Mycotoxins in Vitis vinifera Wines. Am. J. Enol. Vitic. 2017, 68, 336-343. [CrossRef]

29. Schothorst, R.; van Egmond, H. Report from SCOOP task 3.2.10 "collection of occurrence data of Fusarium toxins in food and assessment of dietary intake by the population of EU member states". Subtask: Trichothecenes. Toxicol. Lett. 2004, 153, 133-143. [CrossRef] [PubMed]

30. World Health Organization (WHO). Safety evaluation of certain mycotoxins in food. In WHO Food Additives Series 63 and FAO Food and Nutrition; Prepared by the Seventy-Second Report of the Joint FAO/WHO Expert Committee on Food Additives; World Health Organization: Rome, Italy, 2011; pp. 8, 353-365, ISBN 978-92-4-166063-1.

31. Da Rocha, B.; da Chagas, F.; Freire, O.; Feitosa Maia, F.E.; Florindo Guedes, M.I.; Rondina, D.; Edite, M. Mycotoxins and their effects on human and animal health. Food Control 2014, 36, 159-165. [CrossRef]

32. Prieto-Simón, B.; Campàs, M.; Marty, J.; Noguer, T. Novel highly-performing immunosensor-based strategy for ochratoxin A detection in wine samples. Biosens. Bioelectron. 2008, 23, 995-1002. [CrossRef] [PubMed]

33. Alarcón, S.; Micheli, L.; Palleschi, G.; Compagnone, D. Development of an Electrochemical Immunosensor for Ochratoxin A. Anal. Lett. 2004, 37, 1545-1558. [CrossRef]

34. Vidal, J.; Bonel, L.; Ezquerra, A.; Duato, P.; Castillo, J. An electrochemical immunosensor for ochratoxin A determination in wines based on a monoclonal antibody and paramagnetic microbeads. Anal. Bioanal. Chem. 2012, 403, 1585. [CrossRef] [PubMed]

35. Novo, P.; Moulas, G.; França Prazeres, D.; Chu, V.; Conde, J. Detection of ochratoxin A in wine and beer by chemiluminescence-based ELISA in microfluidics with integrated photodiodes. Sens. Actuators B Chem. 2013, 176, 232-240. [CrossRef]

36. Pagkali, V.; Petrou, P.; Salapatas, A.; Makarona, E.; Peters, J.; Haasnoot, W.; Jobst, G.; Economou, A.; Misiakos, K.; Raptis, I.; et al. Detection of ochratoxin A in beer samples with a label-free monolithically integrated optoelectronic biosensor. J. Hazard. Mater. 2017, 323, 75-83. [CrossRef] [PubMed]

37. Su, X.; Zong, Y.; Richter, R.; Knoll, W. Enzyme immobilization on poly(ethylene-co-acrylic acid) films studied by quartz crystal microbalance with dissipation monitoring. J. Colloid Interface Sci. 2005, 287, 35-42. [CrossRef] [PubMed]

38. Karczmarczyk, A.; Haupt, K.; Feller, K.H. Development of a QCM-D biosensor for Ochratoxin A detection in red wine. Talanta 2017, 166, 193-197. [CrossRef] [PubMed]

39. Lin, D.; Tang, T.; Harrison, D.; Lee, W.; Jemere, A.B. A regenerating ultrasensitive electrochemical impedance immunosensor for the detection of adenovirus. Biosens. Bioelectron. 2015, 68, 129-134. [CrossRef] [PubMed]

40. Jarocka, U.; Sawicka, R.; Góra-Sochacka, A.; Sirko, A.; Zagórski-Ostoja, W.; Radecki, J.; Radecka, H. Electrochemical immunosensor for detection of antibodies against influenza A virus H5N1 in hen serum. Biosens. Bioelectron. 2014, 55, 301-306. [CrossRef] [PubMed]

41. Tang, J.; Huang, Y.; Zhang, C.; Liu, H.; Tang, D. Amplified impedimetric immunosensor based on instant catalyst for sensitive determination of ochratoxin A. Biosens. Bioelectron. 2016, 86, 386-392. [CrossRef] [PubMed] 
42. Luan, Y.; Chen, J.; Li, C.; Xie, G.; Fu, H.; Ma, Z.; Lu, A. Highly Sensitive Colorimetric Detection of Ochratoxin A by a Label-Free Aptamer and Gold Nanoparticles. Toxins 2015, 7, 5377-5385. [CrossRef] [PubMed]

43. Yin, X.; Wang, S.; Liu, X.; He, C.; Tang, Y.; Li, Q.; Liu, J.; Su, H.; Tan, T.; Dong, Y. Aptamer-based Colorimetric Biosensing of Ochratoxin A in Fortified White Grape Wine Sample Using Unmodified Gold Nanoparticles. Anal. Sci. 2017, 33, 659-664. [CrossRef] [PubMed]

44. Gu, C.; Long, F.; Zhou, X.; Shi, H. Portable detection of Ochratoxin A in red wine based on a structure-switching aptamer using a personal glucometer. RSC Adv. 2016, 6, 29563-29569. [CrossRef]

45. Castillo, G.; Lamberti, I.; Mosiello, L.; Hianik, T. Impedimetric DNA Aptasensor for Sensitive Detection of Ochratoxin A in Food. Electroanalysis 2012, 24, 512-520. [CrossRef]

46. Bueno, D.; Valdez, L.; Gutiérrez Salgado, J.M.; Marty, J.; Muñoz, R. Colorimetric Analysis of Ochratoxin A in Beverage Samples. Sensors 2016, 16, 1888. [CrossRef] [PubMed]

47. Budavari, S. The Merck Index: An Encyclopedia of Chemicals, Drugs, and Biologicals, 12th ed.; Budavari, S., O’Neil, M., Smith, A., Heckelman, P., Kinneary, J., Eds.; Merck Research Laboratories Division of Merck \& Co.: Whitehouse Station, NJ, USA, 1996, ISBN 978-0911910124.

48. Bueno, D.; Muñoz, R.; Marty, J. Fluorescence analyzer based on smartphone camera and wireless for detection of Ochratoxin A. Sens. Actuators B Chem. 2016, 232, 462-468. [CrossRef]

49. Bai, X.; Zhang, T.; Qu, Z.; Li, H.; Yang, Z. Contribution of filamentous fungi to the musty odorant 2,4,6-trichloroanisole in water supply reservoirs and associated drinking water treatment plants. Chemosphere 2017, 182, 223-230. [CrossRef] [PubMed]

50. Suarez, A.; Peña-Neira, B.; Fernández de Simón, M.; García-Vallejo, T.; Hernández, E.; Cadahía, J. Presence of cork-taint responsible compounds in wines and their cork stoppers. Eur. Food Res. Technol. 2000, 211, 257-261. [CrossRef]

51. Chatonnet, P.; Bonnet, S.; Boutou, S.; Labadie, M. Identification and responsibility of 2,4,6-tribromoanisole in musty, corked odors in wine. J. Agric. Food Chem. 2004, 52, 1255-1262. [CrossRef] [PubMed]

52. Sefton, M.; Simpson, R. Compounds causing cork taint and the factors affecting their transfer from natural cork closures to wine-A review. Aust. J. Grape Wine Res. 2005, 11, 226-240. [CrossRef]

53. Takeuchi, H.; Kato, H.; Kurahashi, T. 2,4,6-trichloroanisole is a potent suppressor of olfactory signal transduction. Proc. Natl. Acad. Sci. USA 2013, 110, 16235-16240. [CrossRef] [PubMed]

54. Juanola, R.; Guerrero, L.; Subirà, D.; Salvadó, V.; Insa, S.; Garcia Regueiro, J.; Anticó, E. Relationship between sensory and instrumental analysis of 2,4,6-trichloroanisole in wine and cork stoppers. Anal. Chim. Acta 2004, 513, 291-297. [CrossRef]

55. Fontana, A. Analytical methods for determination of cork-taint compounds in wine. Trends Anal. Chem. 2012, 37, 135-147. [CrossRef]

56. Slabizki, P.; Fischer, C.; Legrum, C.; Schmarr, H. Characterization of Atypical Off-Flavor Compounds in Natural Cork Stoppers by Multidimensional Gas Chromatographic Techniques. J. Agric. Food. Chem. 2015, 63, 7840-7848. [CrossRef] [PubMed]

57. Pizarro, C.; Pérez-del-Notario, N.; González-Sáiz, J. Optimisation of a microwave-assisted extraction method for the simultaneous determination of haloanisoles and halophenols in cork stoppers. J. Chromatogr. A 2007, 1149, 138-144. [CrossRef] [PubMed]

58. Anonymous. Cork Stoppers-Determination of Releasable 2,4,6-Trichloroanisol (TCA), 2014; ISO20752:2014(E); International Organization for Standardization: Geneva, Switzerland, 2014.

59. Anonymous. Determination of Releasable 2,4,6-Trichloroanisole in Wine by Cork Stoppers; Method OIV-MA-AS315-16; Compendium of International Analysis of Methods: Paris, France, 2009.

60. Vlachos, P.; Kampioti, A.; Kornaros, M.; Lyberatos, G. Matrix effect during the application of a rapid method using HS-SPME followed by GC-ECD for the analysis of 2,4,6-TCA in wine and cork soaks. Food Chem. 2007, 105, 681-690. [CrossRef]

61. Jeleń, H.; Dziadas, M.; Majcher, M. Different headspace solid phase microextraction-gas chromatography/mass spectrometry approaches to haloanisoles analysis in wine. J. Chromatogr. A 2013, 1313, 185-193. [CrossRef] [PubMed]

62. Taylor, M.; Young, T.; Butzke, C.E. Supercritical fluid extraction of 2,4,6-trichloroanisole from cork stoppers. J. Agric. Food Chem. 2000, 48, 865-871. [CrossRef] 
63. Cacho, J.; Campillo, N.; Viñas, P.; Hernández-Córdoba, M. Cloud point extraction and gas chromatography with direct microvial insert thermal desorption for the determination of haloanisoles in alcoholic beverages. Talanta 2016, 160, 282-288. [CrossRef] [PubMed]

64. Gómez-Ariza, J.; García-Barrera, T.; Lorenzo, F.; Beltrán, R. Use of multiple headspace solid-phase microextraction and pervaporation for the determination of off-flavours in wine. J. Chromatogr. A 2006, 1112, 133-140. [CrossRef] [PubMed]

65. Tarasov, A.; Rauhut, D.; Jung, R. “Cork taint” responsible compounds. Determination of haloanisoles and halophenols in cork matrix: A review. Talanta 2017, 175, 82-92. [CrossRef] [PubMed]

66. Sanvicens, N.; Sánchez-Baeza, F.; Marco, M. Immunochemical determination of 2,4,6-trichloroanisole as the responsible agent for the musty odor in foods. 1. Molecular modeling studies for antibody production. J. Agric. Food Chem. 2003, 51, 3924-3931. [CrossRef] [PubMed]

67. Sanvicens, N.; Varela, B.; Marco, M. Immunochemical determination of 2,4,6-trichloroanisole as the responsible agent for the musty odor in foods. 2. Immunoassay evaluation. J. Agric. Food Chem. 2003, 51, 3932-3939. [CrossRef] [PubMed]

68. Varelas, V.; Sanvicens, N.; Pilar-Marco, M.; Kintzios, S. Development of a cellular biosensor for the detection of 2,4,6-trichloroanisole (TCA). Talanta 2011, 84, 936-940. [CrossRef] [PubMed]

69. Moschopoulou, G.; Kintzios, S. Application of "membrane-engineering" to bioelectric recognition cell sensors for the ultra-sensitive detection of superoxide radical: A novel biosensor principle. Anal. Chim. Acta 2006, 573-574, 90-96. [CrossRef] [PubMed]

70. Moschopoulou, G.; Vitsa, K.; Bem, F.; Vassilakos, N.; Perdikaris, A.; Blouhos, P.; Yialouris, C.; Frosyniotis, D.; Anthopoulos, I.; Mangana, O.; et al. Engineering of the membrane of fibroblast cells with virus-specific antibodies: A novel biosensor tool for virus detection. Biosens. Bioelectron. 2008, 24, 1033-1036. [CrossRef] [PubMed]

71. Kokla, A.; Blouchos, P.; Livaniou, E.; Zikos, C.; Kakabakos, S.; Petrou, P.; Kintzios, S. Visualization of the membrane engineering concept: Evidence for the specific orientation of electroinserted antibodies and selective binding of target analytes. J. Mol. Recognit. 2013, 26, 627-632. [CrossRef] [PubMed]

72. Kintzios, S.; Pistola, E.; Panagiotopoulos, P.; Bomsel, M.; Alexandropoulos, N.; Bem, F.; Ekonomou, G.; Biselis, J.; Levin, R. Bioelectric recognition assay (BERA). Biosens. Bioelectron. 2001, 16, 325-336. [CrossRef]

73. Kintzios, S.; Pistola, E.; Konstas, J.; Bem, F.; Matakiadis, T.; Alexandropoulos, N.; Biselis, I.; Levin, R. The application of the bioelectric recognition assay for the detection of human and plant viruses: Definition of operational parameters. Biosens. Bioelectron. 2001, 16, 467-480. [CrossRef]

74. Apostolou, T.; Moschopoulou, G.; Kolotourou, E.; Kintzios, S. Assessment of in vitro dopamine-neuroblastoma cell interactions with a bioelectric biosensor: Perspective for a novel in vitro functional assay for dopamine agonist/antagonist activity. Talanta 2017, 170, 69-73. [CrossRef] [PubMed]

75. Apostolou, T.; Pascual, N.; Marco, M.; Moschos, A.; Petropoulos, A.; Kaltsas, G.; Kintzios, S. Extraction-less, rapid assay for the direct detection of 2,4,6-trichloroanisole (TCA) in cork samples. Talanta 2014, 125, 336-340. [CrossRef] [PubMed]

76. Moore, E.; Pravda, M.; Guilbault, C. Development of a biosensor for the quantitative detection of 2,4,6-trichloroanisole using screen printed electrodes. Anal. Chim. Acta 2003, 484, 15-24. [CrossRef]

77. Duarte, M.; Lozano-Sanchez, P.; Katakis, I. Copper UPD as non-specific adsorption barrier in electrochemical displacement immunosensors. Biosens. Bioelectron. 2009, 24, 2205-2210. [CrossRef] [PubMed]

78. Freitas, P.; Dias, L.; Peres, A.; Sousa, M.; Castro, L.; Veloso, A. Determination of 2,4,6-trichloroanisole by cyclic voltammetry. Procedia Eng. 2012, 47, 1125-1128. [CrossRef]

79. Peres, A.; Freitas, P.; Dias, L.; Sousa, M.; Castro, L.; Veloso, A. Cyclic voltammetry: A tool to quantify 2,4,6-trichloroanisole in aqueous samples from cork planks boiling industrial process. Talanta 2013, 117, 438-444. [CrossRef] [PubMed]

80. Garcia, A.; Lopes, L.; Brito de Barros, R.; Ilharco, L. The problem of 2,4,6-trichloroanisole in cork planks studied by attenuated total reflection infrared spectroscopy: Proof of concept. J. Agric. Food Chem. 2015, 63, 128-135. [CrossRef] [PubMed]

81. Lorenzo, C.; Zalacain, A.; Alonso, G.; Salinas, M. Non-destructive method to determine halophenols and haloanisoles in cork stoppers by headspace sorptive extraction. J. Chromatogr. A 2006, 1114, $250-254$. [CrossRef] [PubMed] 
82. Márquez-Sillero, I.; Cárdenas, S.; Valcárcel, M. Headspace-multicapillary column-ion mobility spectrometry for the direct analysis of 2,4,6-trichloroanisole in wine and cork samples. J. Chromatogr. A 2012, 1265, 149-154. [CrossRef] [PubMed]

83. Fischer, C.; Fischer, U. Analysis of cork taint in wine and cork material at olfactory subthreshold levels by solid phase microextraction. J. Agric. Food Chem. 1997, 45, 1995-1997. [CrossRef]

84. Vestner, J.; de Revel, G.; Krieger-Weber, S.; Rauhut, D.; du Toit, M.; de Villiers, A. Toward automated chromatographic fingerprinting: A non-alignment approach to gas chromatography mass spectrometry data. Anal. Chim. Acta 2016, 911, 42-58. [CrossRef] [PubMed]

85. Pizarro, C.; Sáenz-González, C.; Pérez-del-Notario, N.; González-Sáiz, J. Microwave assisted extraction combined with dispersive liquid-liquid microextraction as a sensitive sample preparation method for the determination of haloanisoles and halophenols in cork stoppers and oak barrel sawdust. Food Chem. 2012, 132, 2202-2210. [CrossRef]

(C) 2018 by the authors. Licensee MDPI, Basel, Switzerland. This article is an open access article distributed under the terms and conditions of the Creative Commons Attribution (CC BY) license (http:/ / creativecommons.org/licenses/by/4.0/). 